\title{
Anti-Müllerian hormone in grazing dairy cows: Identification of factors affecting plasma concentration, relationship with phenotypic fertility, and genome-wide associations
}

\author{
M. Gobikrushanth, ${ }^{1,2} \odot$ D. C. Purfield, ${ }^{2}$ E. R. Canadas, ${ }^{2}$ M. M. Herlihy, ${ }^{2} \oplus$ J. Kenneally, ${ }^{2} \odot$ M. Murray, ${ }^{3}$ \\ F. J. Kearney, ${ }^{4}$ M. G. Colazo, ${ }^{5} \odot$ D. J. Ambrose, ${ }^{1,5} \odot$ and S. T. Butler ${ }^{2 *} \odot$ \\ ${ }^{1}$ Department of Agricultural, Food and Nutritional Science, University of Alberta, Edmonton, AB, Canada T6G 2P5 \\ ${ }^{2}$ Teagasc, Animal \& Grassland Research and Innovation Centre, Moorepark, Fermoy, Co. Cork, Ireland, P61 C996 \\ ${ }^{3}$ Teagasc, Grange, Dunsany, Co. Meath, Ireland, C15 PW93 \\ ${ }^{4}$ Irish Cattle Breeding Association, Highfield House, Shinagh, Bandon, Co. Cork, Ireland, P72 X050 \\ ${ }^{5}$ Livestock Systems Section, Alberta Agriculture and Forestry, Edmonton, AB, Canada T6H 5T6
}

\section{ABSTRACT}

The objectives of this study were to (1) characterize the distribution and variability of plasma antiMüllerian hormone (AMH) concentration; (2) evaluate factors associated with phenotypic variation in plasma AMH; (3) examine the associations between categories of plasma AMH and reproductive outcomes [pregnancy to first artificial insemination (P/AI), and pregnancy rates within 21,42 , and $84 \mathrm{~d}$ after the mating start date (MSD)]; (4) estimate pedigree and genomic heritability for plasma AMH; and (5) identify and validate SNP associated with phenotypic variation in plasma $\mathrm{AMH}$. Plasma AMH concentration $(\mathrm{pg} / \mathrm{mL})$ was determined from a blood sample collected (mean \pm standard deviation) $10 \pm 2 \mathrm{~d}$ after first insemination at detected estrus (IDE) in 2,628 first- and second-parity Irish dairy cows. Overall, plasma AMH had a positively skewed distribution with mean ( \pm standard deviation), median, minimum, and maximum concentrations of $326 \pm 231$, 268,15 , and $2,863 \mathrm{pg} / \mathrm{mL}$, respectively. Plasma $\mathrm{AMH}$ was greatest for Jersey, followed by Holstein $\times$ Jersey, Holstein $\times$ Norwegian Red, and Holstein cows (410, 332,284 , and $257 \mathrm{pg} / \mathrm{mL}$, respectively). Second-parity cows had greater plasma AMH than first-parity cows (333 vs. $301 \mathrm{pg} / \mathrm{mL}$, respectively). Samples collected at 7 and $8 \mathrm{~d}$ after first IDE had lesser plasma AMH than those collected on d 9, 10, 11, 12, and 13 after first IDE (291 and 297 vs. 317, 319, 331, 337, and $320 \mathrm{pg} /$ $\mathrm{mL})$. Plasma AMH was not associated with either body condition score at first IDE or the interval from calving to MSD. Cows were categorized into low $(\leq 150 \mathrm{pg} /$ $\mathrm{mL} ; \mathrm{n}=526$; lowest $20 \%)$, intermediate $(>150$ to $\leq 461$ $\mathrm{pg} / \mathrm{mL} ; \mathrm{n}=1,576$; intermediate $60 \%$ ), and high $\mathrm{AMH}$

Received May 16, 2019.

Accepted July 19, 2019.

*Corresponding author: stephen.butler@teagasc.ie
(>461 pg/mL; $\mathrm{n}=526$; highest $20 \%)$ groups based on plasma AMH, and associations with reproductive outcomes were tested. Cows with high and intermediate plasma AMH had 1.42- and 1.51-times-greater odds of becoming pregnant within $84 \mathrm{~d}$ after the MSD than those with low plasma AMH (90.3 and 90.8 vs. $86.8 \%$, respectively); however, $\mathrm{P} / \mathrm{AI}$ and pregnancy rate within 21 and $42 \mathrm{~d}$ after the MSD did not differ among AMH categories. Plasma AMH was moderately heritable (pedigree heritability of $0.40 \pm 0.06$ and genomic heritability of $0.45 \pm 0.05$ ), and 68 SNP across Bos taurus autosomes 7 and 11 were associated with phenotypic variation in plasma AMH. Out of 68 SNP, 42 were located in a single quantitative trait locus on Bos taurus autosome 11 that harbored 6 previously identified candidate genes (NR5A1, HSPA5, CRB2, DENND1A, NDUFA8, and PTGS) linked to fertilityrelated phenotypes in dairy cows.

Key words: ovarian reserve, reproductive phenotype, antral follicle count, genome-wide association study

\section{INTRODUCTION}

Anti-Müllerian hormone (AMH), a dimeric glycoprotein produced by granulosa cells of growing preantral and antral follicles (La Marca and Volpe. 2006), is a marker of ovarian reserve in dairy cows (Rico et al., 2009). Recent studies have reported that circulating AMH concentrations were highly variable among cows and strongly repeatable within the same cow (Rico et al., 2009; Ribeiro et al., 2014; Souza et al., 2015; Gobikrushanth et al., 2017). Variations in blood AMH concentration in cattle were associated with maternal nutritional status, subspecies, breed, and lactation number (Mossa et al., 2013; Batista et al., 2014; Ribeiro et al., 2014; Gobikrushanth et al., 2018).

An association between circulating AMH and fertility outcomes has been reported in cows subjected to in- 
semination at detected estrus (IDE) or natural service (Ribeiro et al., 2014), but not in cows subjected to timed AI protocols (Baruselli et al., 2015; Jimenez-Krassel et al., 2015; Gobikrushanth et al., 2018). Ribeiro et al. (2014) reported that cows with the lowest plasma AMH concentrations $(\leq 140 \mathrm{pg} / \mathrm{mL})$ had greater embryo mortality after timed AI (17 vs. 9 and $8 \%$ ) and lower pregnancy rate (69 vs. 75 and $82 \%$ ) after subsequent breeding events that occurred following spontaneous estrus (re-insemination and natural service) compared with cows that had intermediate $(>140$ to $\leq 450 \mathrm{pg} /$ $\mathrm{mL})$ or the highest $(>451 \mathrm{pg} / \mathrm{mL})$ plasma AMH concentrations, respectively. Similarly, Gobikrushanth et al. (2018) reported that cows with low plasma AMH concentrations $(<83 \mathrm{pg} / \mathrm{mL})$ had numerically lower pregnancy to first AI (P/AI) after IDE compared with cows with intermediate $(\geq 83$ to $\leq 285 \mathrm{pg} / \mathrm{mL})$ or high $(>285 \mathrm{pg} / \mathrm{mL})$ plasma AMH concentrations (24 vs. 32 and $34 \%$, respectively). It has been speculated that the use of timed AI protocols potentially overrides the association between circulating AMH and fertility by synchronization of follicular growth and ovulation in cows with low AMH concentrations, and thereby resulting in comparable fertility outcomes for cows with low circulating AMH compared with cows with intermediate or high circulating AMH concentrations. Hence, additional studies are warranted in a larger population of dairy cows IDE to further elucidate the relationship between circulating $\mathrm{AMH}$ and fertility. In Ireland, most cows are managed under a pasture-based, seasonal-calving system and are bred following detected estrus during a 12-wk breeding season following a farm-specific mating start date (MSD). This provides an ideal environment to test the relationship between circulating AMH concentration and fertility in a large cohort of dairy cows subjected to IDE.

In an earlier study (Gobikrushanth et al., 2018), we reported that circulating $\mathrm{AMH}$ concentration was moderately heritable in Canadian Holstein cows (mean \pm SEM; $0.46 \pm 0.31$ ); however, the number of cows (n $=198$ ) available for estimation of heritability was too small to make a strong statistical inference. A heritability estimate of $0.36 \pm 0.03$ was later reported for circulating $\mathrm{AMH}$ using a larger population $(\mathrm{n}=2,905)$ of Holstein heifers (Nawaz et al., 2018). Thus, heritability of circulating AMH remains to be established using a large population of dairy cows. In addition, the aforementioned studies (Gobikrushanth et al., 2018; Nawaz et al., 2018) identified numerous SNP associated with phenotypic variation in circulating $\mathrm{AMH}$ in dairy cows and heifers, respectively, through genome-wide association studies (GWAS). A similar study to identify SNP associated with variation in circulating AMH in Irish Holstein-Friesian cows is of interest because of the differences in genetic background and management system. For example, identification of SNP (genetic markers) associated with variation in circulating $\mathrm{AMH}$ would potentially help to identify, and preselect at birth, future elite genetic merit donors with greater fertility or embryo production potential for use in either multiple ovulation embryo transfer or oocyte pick-up/ in vitro fertilization programs in dairy cattle

We tested the hypothesis that cows with low circulating AMH subjected to IDE have poorer fertility than cows with intermediate or high circulating $\mathrm{AMH}$, and that genetic markers (SNP) are associated with phenotypic variation in circulating AMH. Therefore, the objectives were to (1) characterize the distribution and variability of plasma AMH concentration; (2) evaluate factors associated with phenotypic variation in plasma AMH; (3) examine the association between categories of plasma $\mathrm{AMH}$ and reproductive outcomes (P/AI, pregnancy rate within 21,42 , and $84 \mathrm{~d}$ after the MSD); (4) estimate pedigree and genomic heritability for plasma $\mathrm{AMH}$; and (5) identify and validate SNP associated with phenotypic variation in plasma AMH in Irish dairy cows.

\section{MATERIALS AND METHODS}

\section{Animals and Management}

This study was conducted on 35 seasonal-calving, pasture-based dairy herds located in the province of Munster, Ireland, during the spring calving seasons of 2015 and 2016. The study population included 2,628 dairy cows (1,588 first parity and 1,040 second parity) with 1,844 Holstein, 640 Holstein $\times$ Jersey, 126 Holstein $\times$ Norwegian Red, and 18 Jersey cows. All experimental procedures were approved by the Teagasc Animal Ethics Committee and authorized by the Health Products Regulatory Authority, which is the competent authority in Ireland responsible for the implementation of European Union legislation (Directive 2010/63/EU) for the protection of animals used for scientific purposes.

\section{Definition for Reproductive Parameters}

All cows calved during the spring calving seasons of 2015 or 2016, and mating by AI commenced on a farmspecific fixed calendar date, termed MSD. Detection of estrus was conducted using the standard reproductive management protocols within each farm, which typically involved 2 to 4 periods of visual observation of cows aided by assessment of tail paint removal. Artificial insemination procedures varied between farms, and AI was performed by either a commercial AI technician or by a trained and qualified member of the farm staff. 
The total duration of the breeding season was approximately 84 d. Pregnancy diagnosis using transrectal ultrasound was conducted 5 to $7 \mathrm{wk}$ after the end of the breeding period by a single experienced member of the research team, and embryo/fetus age was estimated for pregnant cows. Conception date for pregnant cows was determined using breeding records and confirmed with the ultrasound information. Pregnant to first AI was coded as 1 if a cow was diagnosed as becoming pregnant for the first AI. Cows that (a) were diagnosed as nonpregnant at the end of the breeding period or (b) received more than one AI and the ultrasound estimate of embryo/fetus age indicated pregnancy was not as a result of first AI were allocated a P/AI code of 0 . Similarly, 21-d pregnancy rate was coded as 1 if a cow received at least one AI within the first $21 \mathrm{~d}$ of the breeding season and was subsequently confirmed as pregnant. Cows that (a) were diagnosed nonpregnant at the end of the breeding period or (b) had an AI event after the first $21 \mathrm{~d}$ of the breeding period and the ultrasound estimate of embryo/fetus age indicated pregnancy was not established during the first $21 \mathrm{~d}$ of the breeding period were coded 0 for 21-d pregnancy rate. Similar criteria were applied for 42 -d and $84-\mathrm{d}$ pregnancy rates.

\section{Definition for Interval from Calving to MSD and BSC Categories}

Cows were ranked based on the interval in days from calving to MSD, and categorized as early calving ( $\geq 80$ $\mathrm{d} ; \mathrm{n}=833$ ), mid calving ( $>60$ to $<80 \mathrm{~d}$; $\mathrm{n}=1,032$ ), or late calving $(\leq 60 \mathrm{~d} ; \mathrm{n}=763)$. Body condition scores were determined at first IDE on a 1-5 scale measured in increments of 0.25 units $(1=$ thin, $5=$ fat $)$ as previously described (Edmonson et al., 1989). Cows were grouped into 4 BCS categories $(\leq 2.50 ; \mathrm{n}=269,2.75 ; \mathrm{n}$ $=1,072,3.00 ; \mathrm{n}=1,067$, and $\geq 3.25 ; \mathrm{n}=220)$.

\section{Blood Sampling and Determination of Plasma Concentrations of $\mathrm{AMH}$}

Each herd was visited once per week during the first 6 wk of the breeding season. A single blood sample was collected between 7 and $13 \mathrm{~d}$ after first IDE from the coccygeal blood vessels using evacuated blood tubes (lithium heparin Vacutainers; Becton Dickinson and Co., Franklin Lakes, NJ) for AMH determination. After collection, plasma tubes were stored in a cooler box containing ice packs until return to the laboratory $(1$ to $4 \mathrm{~h})$ and then centrifuged at $1,500 \times g$ for 20 min at $4^{\circ} \mathrm{C}$; plasma was then harvested and frozen at $-20^{\circ} \mathrm{C}$ until assayed for AMH. Plasma concentrations
( $\mathrm{pg} / \mathrm{mL})$ of AMH were analyzed using the Ansh Labs (Webster, TX) Bovine AMH ELISA using a Dynex DSX Automated ELISA System (Dynex Technologies, Chantilly, VA). The assay has an analytical measurable range of 13.5 to $2,240 \mathrm{pg} / \mathrm{mL}$. The AMH assay's lowest detection limit is $11 \mathrm{pg} / \mathrm{mL}$, and intra- and interassay coefficients of variation $(\mathbf{C V})$ were $<5 \%$.

\section{Genotyping, Quality Control, and Imputation}

Of the 2,628 cows with AMH information, 1,725 cows that were classified as $\geq 75 \%$ Holstein-Friesian (hereafter referred to as Holstein) also had genotype information available. These 1,725 cows were genotyped on a variety of panels including the Illumina Low Density panel $(\mathrm{n}=99$; $\mathrm{SNP}=6,909$; Illumina Inc., San Diego, CA) or the Illumina custom genotyping panel International Dairy and Beef version $1(\mathrm{n}=66$; SNP $=17,137)$, version $2(\mathrm{n}=1,155 ; \mathrm{SNP}=18,004)$ or version $3(\mathrm{n}=405 ; \mathrm{SNP}=53,450)$. All cows had a call rate $\geq 90 \%$, and only autosomal SNP, SNP with a known chromosome and position on the ARS-UCD 1.2 build (https://www.ncbi.nlm.nih.gov/assembly/GCA _002263795.2; accessed August 27, 2019), and SNP with a call rate $\geq 90 \%$ were retained. To increase the density of the SNP panel for GWAS, imputation to the Illumina Bovine high density (HD) BeadChip (Illumina Inc.) was performed using FImpute2 (Sargolzaei et al., 2014). Imputation was completed using a 2-step approach whereby all cows were first imputed to the Illumina BovineSNP50 chip using a reference population of 3,532 Holstein BovineSNP50 genotyped cows, and subsequently imputed to HD using a multi-breed population of 5,504 HD-genotyped cattle as the reference population. In addition, all SNP that had a minor allele frequency $<0.01$ and that deviated significantly from Hardy-Weinberg equilibrium $\left(P<10^{-6}\right)$ were removed. After edits, 636,066 SNP on 1,725 Holstein cows remained available for analysis.

\section{Statistical Analyses}

Data were analyzed using SAS version 9.4 (SAS Institute Inc., Cary, NC). The descriptive statistics and normality for plasma AMH concentration $(\mathrm{pg} / \mathrm{mL})$ were determined using the UNIVARIATE procedure.

To identify factors associated with plasma $\mathrm{AMH}$ concentration (dependent continuous variable), a multivariable model including breed (Holstein, Holstein $x$ Norwegian Red, Holstein $\times$ Jersey, and Jersey), parity (first and second), interval from calving to MSD (categorized as early, mid, or late calving; $\geq 80 \mathrm{~d},>60$ to $<80 \mathrm{~d}$, and $\leq 60 \mathrm{~d}$, respectively), BCS at first IDE 
(categorized as $\leq 2.50,2.75,3.00$, and $\geq 3.25$ ), and day of sampling related to first IDE $(7,8,9,10,11,12$, and $13 \mathrm{~d}$ after first IDE) were used to explain the variability observed in plasma AMH by ANOVA method using the MIXED procedure. The effect of herd was treated as random. Plasma AMH concentration data were first transformed by Box-Cox transformation to meet the assumptions for a Gaussian distribution. The plasma concentrations of AMH (transformed values) were initially modeled against all of the aforementioned categorical variables and their interactions. As none of the interactions were significant, the final model only had the categorical variables modeled against plasma AMH concentration, and the differences in means were tested using the Tukey-Kramer multiple means comparison test. The transformed least squares means results were back transformed for ease of interpretation.

Cows were ranked across herds in ascending order of plasma AMH concentration, and grouped into low $\mathrm{AMH}$ (lowest $20 \%$ values; $\mathrm{n}=526$; mean $=105$; range $=15-150 \mathrm{pg} / \mathrm{mL}$ ), intermediate $\mathrm{AMH}$ (intermediate $60 \%$ values; $\mathrm{n}=1,576 ;$ mean $=278 ;$ range $=151-461$ $\mathrm{pg} / \mathrm{mL}$ ), or high $\mathrm{AMH}$ (highest $20 \%$ values; $\mathrm{n}=526$; mean $=690 ;$ range $=462-2,863 \mathrm{pg} / \mathrm{mL})$ categories The categories of AMH were chosen across breed and parity to take an approach similar to that of Ribeiro et al. (2014) and Gobikrushanth et al. (2018), and to examine the proposed importance of ovarian reserve for fertility (Ireland et al., 2011). An a priori power analysis based on type I error of 0.05 and power of 0.80 called for a minimum of 322 cows per AMH category to determine a difference of 10 percentage units in P/AI (24 vs. $34 \%$ ) between low and high AMH cows, respectively, from our previous study (Gobikrushanth et al., 2018). Thus, the number of cows used per AMH category was adequately powered to test the association with fertility in the current study.

The associations among categories of plasma AMH (low $\mathrm{AMH}$, intermediate $\mathrm{AMH}$, and high $\mathrm{AMH}$ ), breed (Holstein, Holstein $\times$ Norwegian Red, Holstein $\times$ Jersey, and Jersey), parity (first and second), interval from calving to MSD (categorized as early, mid, and late calving; $\geq 80 \mathrm{~d},>60$ to $<80 \mathrm{~d}$, and $\leq 60 \mathrm{~d}$, respectively), BCS at first IDE (categorized as $\leq 2.50,2.75,3.00$, and $\geq 3.25$ ), and reproductive outcomes ( $\mathrm{P} / \mathrm{AI}$ and pregnancy rate within 21,42 , and $84 \mathrm{~d}$ after MSD) were analyzed using the GLIMMIX procedure, and the effect of herd was treated as random. The model specifications included a binomial distribution and logit function and an option to retrieve odds ratios and their confidence intervals. The reproductive outcomes were initially modeled against all of the aforementioned categorical variables and their interactions. As none of the interactions were significant, the final model included only the categorical variables tested against reproductive outcomes. Significant differences were reported if $P \leq 0.05$ and considered to be a tendency if $P>0.05$ and $\leq 0.10$.

\section{Pedigree and Genomic Heritability for AMH and GWAS}

Pedigree variance components of transformed AMH concentrations were estimated by restricted maximum likelihood in ASReml (Gilmour et al., 2009) using a univariate animal model for all 2,628 cows with plasma AMH concentration information. Fixed effects included in the models were parity (classified as first- and second-parity groups), herd, and days when blood sample was collected related to first IDE ( 7 to $13 \mathrm{~d}$ after first IDE). The random effect included the additive genetic effect of the cows. The pedigree of all cows was traced back to the founder population, where founder cows were allocated to breed groups based on breed. The pedigree consisted of 37,175 cows.

Whole-genome association analysis was performed in genome-wide complex trait analysis (Yang et al., 2011) using a mixed linear model based association. The following model was used:

$$
y=\mu+\mathbf{b x}+g^{-}+e,
$$

where $y$ is the Box-Cox transformed AMH dependent variable; $\mu$ is the overall mean; $\mathbf{b}$ is a vector of fixed effects including parity, day relative to AI when blood sample was collected, herd, and the additive effect of the candidate SNP tested for association; $\mathbf{x}$ is the incidence matrix for parameters $\mathbf{b} ; g^{-}$is the accumulated polygenic effect of all SNP; and $e$ is the residual. The genome-wide significance SNP threshold was set at $P \leq$ $5 \times 10^{-8}$ and the suggestive SNP threshold was set at $P$ $\leq 1 \times 10^{-5}$. Gene search was done using Ensembl (http: //ensembl.org/) and the National Center for Biotechnology Information map viewer (https://www.ncbi.nlm .nih.gov/genome/gdv/) on the ARS-UCD 1.2 genome build. The relative roles of nearest candidate genes were searched using both the Bovine Genome Database (http://bovinegenome.org/) and the Human Genome Database (http://www.genecards.org/). In addition, the proportion of phenotypic variance accounted for by all SNP (SNP-based heritability/genomic heritability) was estimated in a subset of 1,725 Irish Holstein cows that had genotype information available using the genomic REML approach, with the same model used for the association analyses in genome-wide complex trait analysis (Yang et al., 2010). 


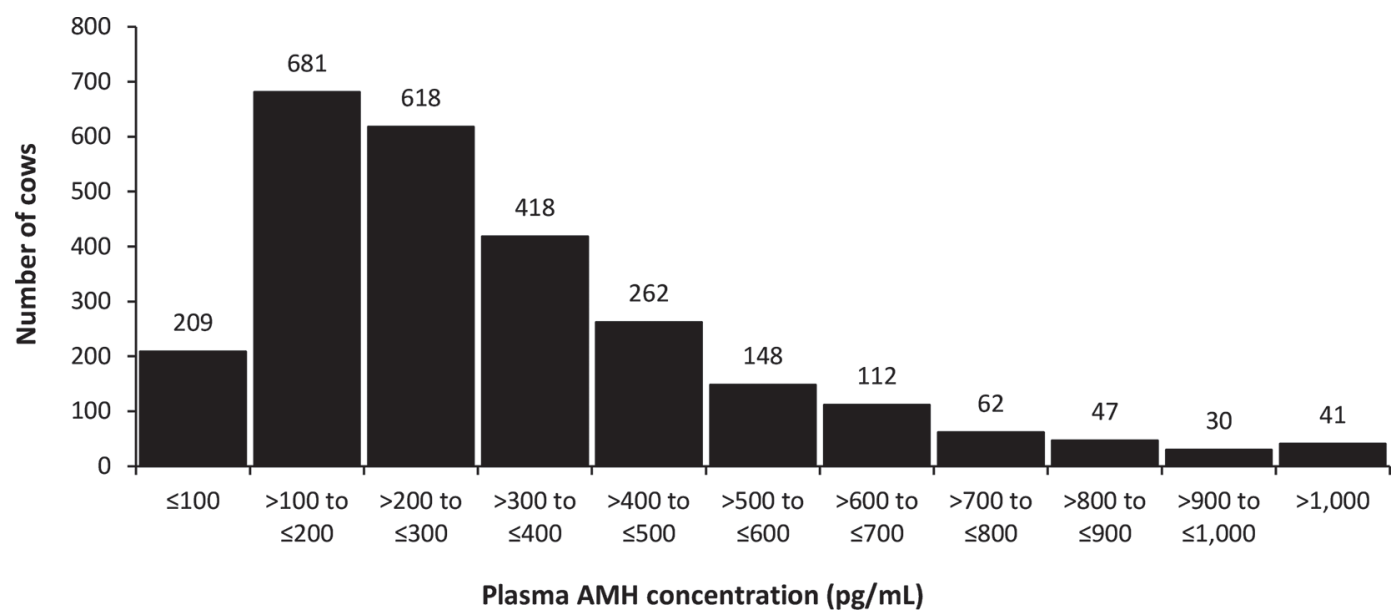

Figure 1. The distribution of plasma anti-Müllerian hormone (AMH) concentration from samples collected between 7 and $13 \mathrm{~d}$ after first insemination at detected estrus (IDE) in 2,628 Irish dairy cows. The lowest and highest plasma AMH concentrations were 15 and 2,863 pg/mL, respectively.

\section{Validation of Associated SNP}

The first approach to validate all 68 suggestively associated SNP identified in this study was to estimate the proportion of phenotypic variance explained by these variants in a separate population of 589 Canadian Holstein cows as described previously (Gobikrushanth et al., 2018). All 589 cows within this validation population were genotyped with the Bovine Geneseek Genomic Profiler 26K Beadchip (Neogen Inc., Lincoln, NE) at Delta Genomics (Edmonton, AB, Canada), and were imputed to HD using the Irish multi-breed population of 5,504 HD-genotyped cattle as the reference population and the ARS UCD 1.2 reference assembly. Box-Cox transformed AMH phenotypes were available on all cows, and information on parity and herd were included as fixed effects. All SNP above the suggestive threshold were used to construct a genomic relationship matrix (and the proportion of phenotypic variance accounted for was estimated using genomic REML in genome-wide complex trait analysis; Yang et al., 2010). To verify that the proportion of variance was greater than that due to chance, a random set of 68 SNP with the same allele frequencies as the suggestively associated SNP were sampled and tested using the same approach as above. This process was repeated 5 times and the proportion of variance explained by the random subset of SNP was then averaged.

\section{RESULTS AND DISCUSSION}

A reproductive phenotype that has high variability, repeatability, and heritability, and strong association with fertility has the potential to become an ideal candidate trait in genetic selection to improve fertility in dairy cows. Plasma AMH concentration had a positively skewed distribution with mean $( \pm \mathrm{SD})$, median, minimum, and maximum concentrations of 326 $\pm 231,268,15$, and $2,863 \mathrm{pg} / \mathrm{mL}$, respectively. The pattern of distribution and variability reported herein (Figure 1) for Irish dairy cows was comparable to that of previous findings in North American dairy cows (10 to $3,198 \mathrm{pg} / \mathrm{mL}$ by Ribeiro et al., 2014; 14 to $774 \mathrm{pg} /$ $\mathrm{mL}$ by Gobikrushanth et al., 2017; 14 to $1,879 \mathrm{pg} / \mathrm{mL}$ by Gobikrushanth et al., 2018) and heifers (2 to 2,000 $\mathrm{pg} / \mathrm{mL}$ by Nawaz et al., 2018) and in Japanese Black cows (32 to $1,992 \mathrm{pg} / \mathrm{mL}$ by Hirayama et al., 2017). Large phenotypic variation for circulating $\mathrm{AMH}$ has also been reported in beef heifers (40 to $1,730 \mathrm{pg} / \mathrm{mL}$; Newberry, 2016). Together, these findings indicate that there is large phenotypic variation in circulating $\mathrm{AMH}$ concentrations in diverse cattle populations. Thus, the first criterion of having high variability to become an ideal candidate trait for genetic selection in dairy cows was fulfilled.

Even though repeatability for plasma AMH was not estimated in the current study, several studies have reported that circulating AMH concentrations were highly repeatable within the same individual dairy cows. For example, repeatability estimates of 0.87 between 4 and $5 \mathrm{~d}$ before estrus and the day of estrus (Rico et al., 2009), 0.90 between d 7 and 15 of a controlled estrous cycle (Ribeiro et al., 2014), 0.77 between proestrus and diestrus stages of an estrous cycle (Souza et al., 2015), and 0.73 between a measurement conducted during the early postpartum period (d 14 postpartum) and a subsequent measurement on the expected day of follicular wave emergence during a timed AI protocol 
approximately 60 d later (Gobikrushanth et al., 2017) have been reported. In addition, Monniaux et al. (2012) reported that the mean circulating $\mathrm{AMH}$ concentrations measured at $8,18,28,38$, and $48 \mathrm{~d}$ postpartum in the same set of cows were remarkably stable $(\sim 100$ $\mathrm{pg} / \mathrm{mL}$ ) despite marked changes in blood nonesterified fatty acid concentrations, indicating that neither day postpartum nor energy balance status was associated with circulating AMH concentration. Collectively, the aforementioned findings indicate that circulating $\mathrm{AMH}$ concentration could be measured during any stage of either an estrous cycle or postpartum period in dairy cows to test associations with fertility outcomes. Thus, circulating AMH concentration fulfills the second criterion of having high repeatability to become an ideal candidate trait for genetic selection in dairy cows.

Both genetic and nongenetic factors could contribute to the phenotypic variation in circulating $\mathrm{AMH}$ in dairy cows. Therefore, it is important to identify nongenetic factors that account for variation before estimation of heritability for plasma AMH concentration. In the current study, plasma AMH concentration was associated with breed, parity, and day of blood sampling relative to first IDE (Figure 2A, B, and E). However, plasma $\mathrm{AMH}$ was not associated with either interval from calving to MSD or BCS at first IDE (Figure 2C and D, respectively). Plasma concentration of $\mathrm{AMH}$ was greatest for Jersey followed by Holstein $\times$ Jersey, Holstein $\times$ Norwegian Red, and Holstein cows (410, 332, 284, and $257 \mathrm{pg} / \mathrm{mL}$, respectively; $P<0.01$; Figure $2 \mathrm{~A}$ ). Ribeiro et al. (2014) also reported that Jersey and Holstein $\times$ Jersey crossbred cows had greater plasma AMH concentrations than Holstein cows (337 and 298 vs. 264 $\mathrm{pg} / \mathrm{mL}$ ), comparable to the plasma AMH concentrations observed in the current study. Second-parity cows had greater plasma AMH than first-parity cows in the current study (333 vs. $301 \mathrm{pg} / \mathrm{mL}$, respectively; $P<$ 0.01 ; Figure 2B), which supports the previous findings of Ribeiro et al. (2014) and Gobikrushanth et al. (2018), who reported that circulating concentrations of $\mathrm{AMH}$ were higher for second- and third-lactation cows compared with first- and fourth-lactation cows. This is likely due to an increase in circulating AMH because of an increase in ovarian follicular recruitment up to 5 yr of age (or third parity), followed by a decrease in $\mathrm{AMH}$ concentration following gradual depletion of the ovarian reserve. Interestingly, similar observations have been reported between age and antral follicle count (AFC) in beef heifers (Cushman et al., 2009) and dairy cows (Mossa et al., 2012). Nevertheless, a longitudinal study investigating AFC or AMH in female cattle from birth to later stages of life might provide a better understanding of the relationship between age and AFC or AMH. Samples collected at 7 and $8 \mathrm{~d}$ after first IDE had slightly lower plasma AMH than those collected on $9,10,11,12$, and $13 \mathrm{~d}$ after first IDE (291 and 297 vs. $317,319,331,337$, and $320 \mathrm{pg} / \mathrm{mL}$, respectively; $P<0.01$; Figure 2E). Rico et al. (2011) reported that plasma AMH concentrations were lower between d 6 and 8 of an estrous cycle compared with the other days when continuously monitored for the first $20 \mathrm{~d}$ of a spontaneous estrous cycle in Holstein cows. Of note, in the current study, samples were not collected from same set of cows at different time points of an estrous cycle (i.e., repeated measurements), but rather were collected between 7 and $13 \mathrm{~d}$ after first IDE in all cows on a convenience basis. Regardless, it is expected that concentrations of AMH closer to the end of a nonovulatory follicular wave would be slightly lower than those measured after emergence of a new follicular wave, as $\mathrm{AMH}$ production is minimal in the dominant follicle compared with that in small and medium-sized antral follicles (Rico et al., 2009). Consequently, the effects of breed and parity of cows and day of blood sampling for plasma AMH related to first IDE were accounted for in the statistical model used to estimate heritability for plasma AMH concentration.

The pedigree heritability estimate for plasma $\mathrm{AMH}$ was 0.40 (SE 0.06) for all cows $(\mathrm{n}=2,628)$ and the genomic heritability for plasma AMH was 0.45 (SE 0.05 ) when estimated only in Irish Holstein cows ( $\mathrm{n}=$ 1,725 ) in the present study. This is similar to our previous finding in Canadian Holstein cows $(0.46 \pm 0.31$; Gobikrushanth et al., 2018) and marginally larger than a heritability estimate reported using 2,905 Holstein heifers (0.36 \pm 0.03 ; Nawaz et al., 2018). Interestingly, the moderate heritability for circulating AMH concentration reported in the current study and previously by Gobikrushanth et al. (2018) and by Nawaz et al. (2018) are comparable to the heritability estimate of 0.31 reported for AFC in dairy cows (Walsh et al., 2014). These findings collectively indicate that both circulating $\mathrm{AMH}$ and $\mathrm{AFC}$ possess moderate heritability in cattle. A moderate heritability reported for circulating $\mathrm{AMH}$ in the current study was much greater than heritability estimates previously reported for traditional or detailed fertility traits in dairy cows. Berry et al. (2014) reported that heritability estimates were 0.02 for firstservice conception rate and number of services, 0.03 for calving interval, 0.04 for days open, and 0.05 for interval from calving to first service in dairy cows and 0.13 and 0.17 for age at first service and age at first calving, respectively, in dairy heifers. Carthy et al. (2015) reported that heritability estimates were 0.07 for calving to first service and 0.10 for early postpartum ovulation. Therefore, the moderate heritability reported for circulating $\mathrm{AMH}$ concentration in the current study and in previous studies (Gobikrushanth et al., 2018; Nawaz et 
al., 2018) at least partly fulfilled the third criterion of having high heritability to become an ideal candidate trait for genetic selection in dairy cows.

In total, 9 SNP passed the genome-wide threshold and 59 SNP passed the suggestive significance threshold, respectively (Figure 3). Of these SNP, 16 were located in a QTL on BTA7 spanning from 21.359 to $21.886 \mathrm{Mb}$, and an additional 42 SNP were located in a QTL on BTA11 from 92.051 to $101.918 \mathrm{Mb}$. The list of nearest candidate genes identified for each significant lead SNP from their respective chromosomes are listed in Table 1. The strongest association with plasma $\mathrm{AMH}$ variation
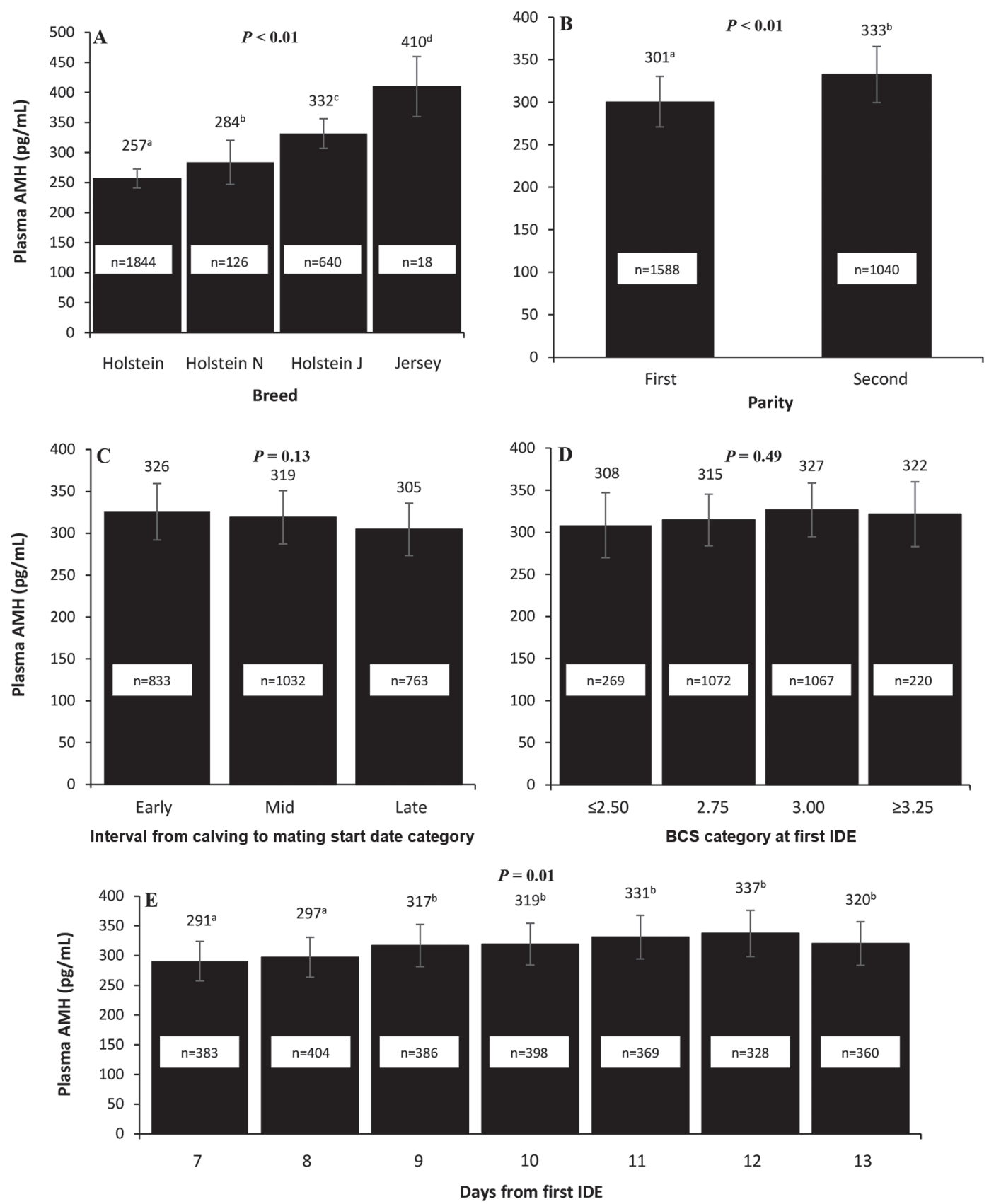

Figure 2. The associations among breed [Holstein, Holstein $\times$ Norwegian Red (N), Holstein $\times$ Jersey $(\mathrm{J})$, and Jersey], parity (first and second), calving to mating start date categories (categorized as early, mid, and late calving; $>80 \mathrm{~d}$, $>60$ to $<80 \mathrm{~d}$, and $<60 \mathrm{~d}$, respectively), BCS at first insemination at detected estrus (IDE) categories (categorized as $\leq 2.50,2.75,3.00$, and $\geq 3.25$ ), day of blood sampling (7, 8, 9, 10, 11, 12, and $13 \mathrm{~d}$ ) after first IDE, and plasma anti-Müllerian hormone (AMH) concentrations in 2,628 Irish dairy cows (A, B, C, D, and E, respectively).

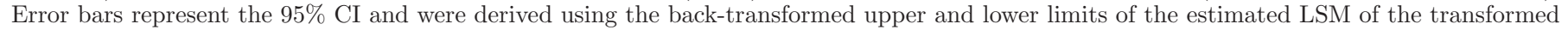
data. Within each panel, different superscript letters a-d indicate that the LSM differ $(P<0.05)$. 
was $\mathrm{rs} 13321135\left(P=3.97 \times 10^{-12}\right)$, an intronic variant located within WDR38 on BTA11. In total, 216 genes were located in this 9.867-Mb QTL region on BTA11, from which NR5A1, HSPA5, CRB2, DENND1A, NDUFA8, and PTGS have been previously identified as candidate genes for fertility-related phenotypes in dairy cows (Taniguchi et al., 2009; Zhang et al., 2011; Jaton et al., 2018). Gene NR5A1 belongs to nuclear receptor subfamily 5 and encodes steroidogenic factor 1 , which plays a key role in the steroidogenic pathway. Taniguchi et al. (2009) reported that NR5A1 contributes to the transcriptional regulation of steroidogenic gene expression and hence progesterone production in the bovine corpus luteum. Heat shock proteins (HSP) are highly conserved in nature and are considered to play a vital role in early embryonic development and fertility. The HSPA5 gene is one of several genes belonging to the HSP70 family and is more highly expressed in blastocysts than in degenerate embryos (Zhang et al., 2011). Moreover, Jaton et al. (2018) conducted a GWAS to examine embryo production traits in Canadian Holstein cows and reported that CRB2, DENND1A, NDUFA8, and PTGS1 were potential positional candidate genes related to the number of embryos produced by donor cows. Most of the aforementioned genes (NR5A1, DENND1A, NDUFA8, and PTGS) were also identified by Nawaz et al. (2018) as SNP associated with circulating $\mathrm{AMH}$ concentration in US Holstein heifers. These findings are intriguing and potentially of importance if circulating $\mathrm{AMH}$ could be considered as a potential fertility trait for selection.

The second strongest SNP associated with AMH concentration was rs43505519 $\left(P=9.41 \times 10^{-12}\right)$, an upstream variant of the $A M H$ gene on BTA7. This variant has also been previously associated with circulating AMH concentration within a Canadian Holstein population (Gobikrushanth et al., 2018), providing strong evidence that the variability in circulating $\mathrm{AMH}$ concentration was associated with the same regulatory variants in different populations of cows. This was reflected in the raw data for plasma $\mathrm{AMH}$ concentration, whereby homozygous $A A$ cows had a median plasma AMH concentration of $356.9 \mathrm{pg} / \mathrm{mL}$, whereas homozygous $G G$ cows had a median plasma AMH concentration of $221.5 \mathrm{pg} / \mathrm{mL}$. The frequency of the favorable $A$ allele at this position was 0.27 , suggesting that there is potential for large genetic gain in plasma AMH concentration if the frequency of this allele could be increased.

To confirm that each of the 68 SNP above the suggestive threshold was a true association, we compared their association results to those obtained in a similar study that identified SNP associated with circulating AMH concentration in a Canadian Holstein population (Gobikrushanth et al., 2018). All 68 SNP identified in the present study were significantly $(P<0.01)$ associated with circulating AMH concentration of the Canadian population of 589 Holstein cows. This evidence was further substantiated when comparing the results

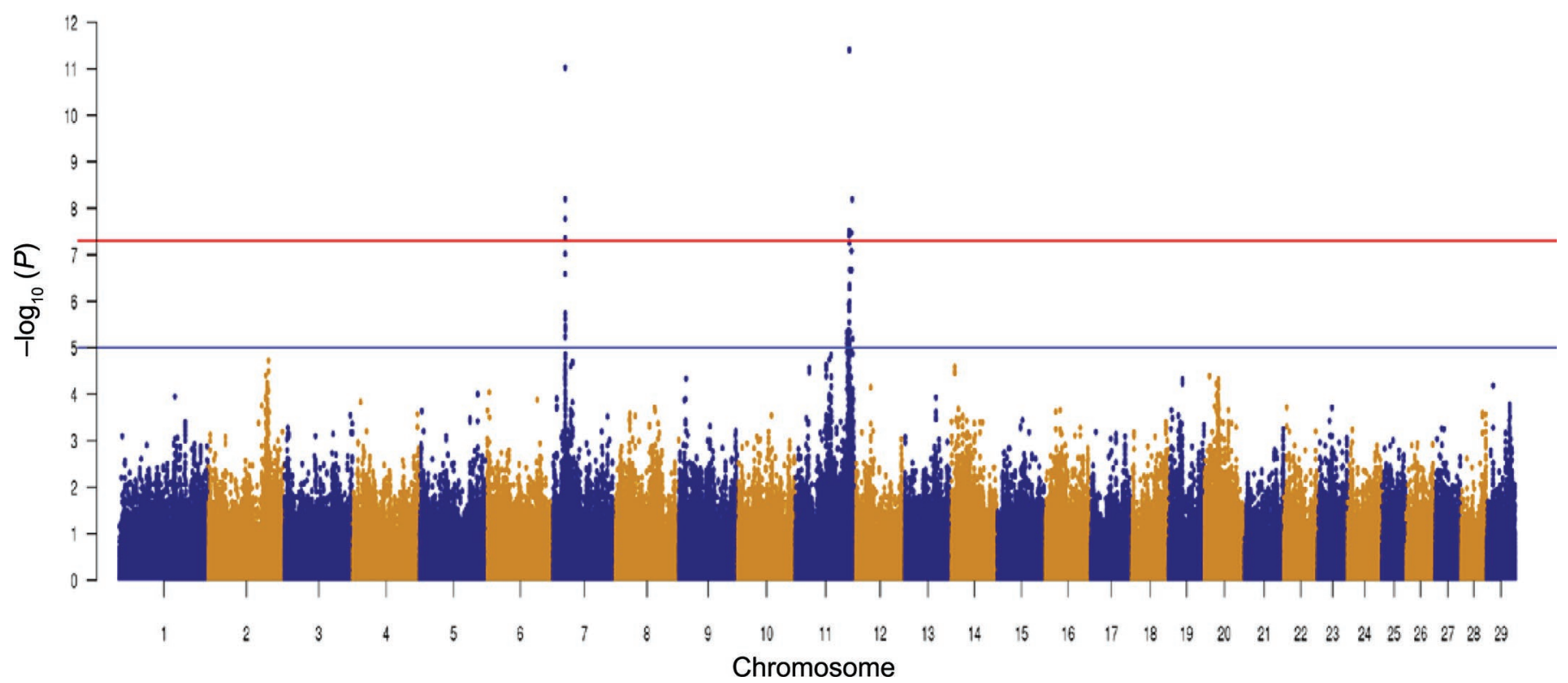

Figure 3. Manhattan plot of the genome-wide association $P$-values for transformed plasma anti-Müllerian hormone (AMH) concentrations across 1,725 genotyped Irish Holstein cows. The red horizontal line indicates 9 SNP with genome-wide significance and the blue horizontal line indicates 59 SNP with suggestive significance across Bos taurus autosomes 7 and 11. 


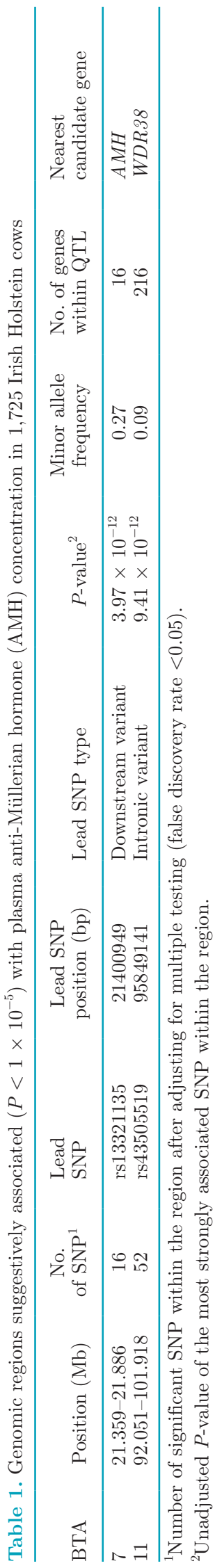

of the present study to that of Nawaz et al. (2018). In this regard, Nawaz et al. (2018) reported 11 significant SNP associations on BTA11 with circulating AMH concentration in Holstein heifers, of which 7 were included in the present study and each had a $P$-value of $<10^{-4}$. This suggests that both QTL on BTA7 and BTA11 were truly QTL associated with circulating AMH concentration, as they have been significantly associated with circulating $\mathrm{AMH}$ in 2 and 3 separate Holstein populations, respectively.

To further validate these SNP associations, we tested the proportion of phenotypic variation that the $68 \mathrm{sug}$ gestive SNP accounted for in the Canadian Holstein population compared with 5 random SNP subsets of the same number. The proportion of variance accounted for by the suggestive SNP was 12.26\% (SE 0.05). This was significantly more than the random SNP subsets, where the proportion of phenotypic variance accounted for ranged from 0.02 to $6.71 \%$. This further substantiates the evidence that the SNP identified in the present study were truly associated with circulating AMH concentration. It is important to note, however, that although a moderate proportion of phenotypic variance was explained by the suggestively associated SNP, a large proportion remained unexplained. We inferred that that the underlying genetic architecture regulating circulating AMH concentration is highly polygenic and that although there are 2 major QTL influencing AMH concentration, most of the variance is due to the additive (and possibly multiplicative) effect of thousands of polymorphisms.

Regardless of having high variability and repeatability, moderate heritability, and QTL associated with phenotypic $\mathrm{AMH}$ and harboring previously identified candidate genes of fertility-related phenotypes, it is important that circulating AMH is also strongly associated with field fertility outcomes before it can be considered a potential fertility trait for genomic selection in dairy cows. The exact role of AMH in reproductive physiology is poorly understood. In a recent review, Dewailly et al. (2014) concluded that AMH plays 2 major functions in women: (1) inhibition of follicular growth from the primordial follicle reserve, averting premature exhaustion of the ovarian follicular reserve; and (2) reduction in the responsiveness of preantral and small antral follicles to FSH, restricting ovarian follicular growth. Moreover, a series of experiments (Jimenez-Krassel et al., 2009; Ireland et al., 2011) reported that cows with low AFC, which typically have a low concentration of $\mathrm{AMH}$, have compromised follicle development and oocyte quality, greater concentration of gonadotropins, lower concentration of progesterone, and lesser endometrial thickness compared with those with high AFC; most of these factors are critically important for establishment and 
Table 2. Distribution of breed and parity and descriptive statistics for interval from calving to mating start date (MSD), BCS at first insemination at detected estrus (IDE), and day of blood sampling for plasma anti-Müllerian hormone determination (AMH) by plasma AMH categories in 2,628 Irish dairy cows

\begin{tabular}{|c|c|c|c|}
\hline Item & $\begin{array}{l}\text { Low } \\
\text { AMH }\end{array}$ & $\begin{array}{c}\text { Intermediate } \\
\text { AMH }\end{array}$ & $\begin{array}{l}\text { High } \\
\text { AMH }\end{array}$ \\
\hline \multicolumn{4}{|l|}{ Breed (no. of cows) } \\
\hline Holstein & 410 & 1,140 & 294 \\
\hline Holstein $\times$ Jersey & 94 & 347 & 199 \\
\hline Jersey & 0 & 11 & 7 \\
\hline \multicolumn{4}{|l|}{ Parity (no. of cows) } \\
\hline Interval from calving to $\mathrm{MSD}$ ( $\mathrm{d}$; mean $\pm \mathrm{SD}$ ) & $66 \pm 30$ & $68 \pm 44$ & $69 \pm 30$ \\
\hline BCS at first IDE (units: mean \pm SD) & $2.90 \pm 0.34$ & $2.87 \pm 0.53$ & $2.88 \pm 0.34$ \\
\hline Day of sampling for plasma AMH related to first IDE (d; mean \pm SD) & $10 \pm 2$ & $10 \pm 2$ & $10 \pm 2$ \\
\hline
\end{tabular}

${ }^{1}$ Plasma AMH concentration was determined in 2,628 first- and second-parity Irish dairy cows of 4 different breed types from 35 herds between 7 and $13 \mathrm{~d}$ after first IDE. Cows were ranked across herds in ascending order by plasma AMH concentration and grouped into low AMH (lowest $20 \%$ values; $\mathrm{n}=526$; mean $=105 ;$ range $=15-150 \mathrm{pg} / \mathrm{mL}$ ), intermediate $\mathrm{AMH}$ (intermediate $60 \%$ values; $\mathrm{n}=1,576 ;$ mean $=278 ;$ range $=$ 151-461 pg/mL), or high AMH (highest $20 \%$ values; $\mathrm{n}=526$; mean $=690$; range $=462-2,863 \mathrm{pg} / \mathrm{mL}$ ) categories.

maintenance of pregnancy. Regardless, the association between circulating AMH and fertility outcomes appears to be restricted to cows subjected to IDE or natural service (Ribeiro et al., 2014) and was not observed in cows subjected to timed AI protocols (Baruselli et al., 2015; Jimenez-Krassel et al., 2015; Gobikrushanth et al., 2018). It was suggested by others (Ribeiro et al., 2014; Baruselli et al., 2015) that the use of timed AI protocols might override the potential association between $\mathrm{AMH}$ and fertility. In this regard, Ribeiro et al. (2014) were one of the first to report that P/AI following a timed AI did not differ among cows (a combination of Holstein, Jersey and Holstein $\times$ Jersey cross bred) with low $(\leq 140)$, intermediate $(>140$ to $\leq 450)$, or high $(>451)$ plasma AMH concentration $(\mathrm{pg} / \mathrm{mL})$; however, there was some evidence that cows in the low AMH category had lower likelihood of pregnancy after reinsemination and natural service at subsequent spontaneous estrus events compared with those in intermediate or high AMH categories (69 vs. 75 and $82 \%$, respectively). Jimenez-Krassel et al. (2015) reported no association between serum AMH concentrations determined in 11- to 15-mo-old Holstein heifers (categorized into quartiles $\mathrm{Q} 1=6.2$ to $30.0 ; \mathrm{Q} 2=30.1$ to 56.0 ; Q3 $=56.1$ to $85.0 ; \mathrm{Q} 4=85.7$ to $432.0 \mathrm{pg} / \mathrm{mL} ; \mathrm{n}=60$ each) and subsequent measures of reproductive success as heifers and as lactating cows (conception rate at first AI, days open, calving interval, and services per conception). Jimenez-Krassel et al. (2015) also reported that the total percentage of lactating cows that became pregnant across parities 1 to 3 combined was significantly lower for cows in the first quartile compared with those in the second or third quartiles, but was not different from cows in the fourth quartile. Baruselli et al. (2015) also failed to detect any association between circulating AMH and age at conception in 528 Holstein heifers or the interval from calving to conception in 223 lactating Holstein cows subjected to timed AI.

In our previous study, we observed no difference in $\mathrm{P} /$ $\mathrm{AI}$ and pregnancy risk up to $250 \mathrm{~d}$ postpartum in cows subjected to timed AI or IDE. However, when cows subjected to IDE were analyzed separately, cows with low serum AMH had numerically lower P/AI compared with cows with intermediate or high $\mathrm{AMH}(24,32$, and $34 \%$, respectively), but that analysis was hampered by small sample size. The latter study led to the current investigation testing the association between circulating $\mathrm{AMH}$ and fertility in a larger population of Irish dairy cows subjected to IDE. The descriptive statistics for number of cows in each breed and parity and mean $( \pm \mathrm{SD})$ for interval from calving to MSD, BCS at first IDE, and day of blood sampling relative to AI for plasma $\mathrm{AMH}$ determination by plasma $\mathrm{AMH}$ category are presented in Table 2 .

In the current study, cows (a combination of Holstein, Jersey, Holstein $\times$ Jersey, and Holstein $\times$ Norwegian Red) with high and intermediate plasma AMH had 1.42- and 1.51-times-greater odds for pregnancy rate within $84 \mathrm{~d}$ after MSD (which coincides with the end of the breeding season) compared with cows with low plasma AMH (90.3 and 90.8 vs. $86.8 \%$, respectively; Table 3) despite no differences in $\mathrm{P} / \mathrm{AI}$ and pregnancy rate within 21 and $42 \mathrm{~d}$ after MSD among plasma AMH categories (Tables 4, 5, and 6, respectively). Similar findings have been reported between AFC categories and fertility in dairy cows subjected to either IDE alone (Mossa et al., 2012) or 6 wk of IDE followed by $6 \mathrm{wk}$ of natural service in a 12 -wk breeding season (Martinez et al., 2016). Mossa et al. (2012) reported that a lower proportion of Holstein-Friesian cows classified as hav- 
Table 3. Associations among categories of plasma anti-Müllerian hormone (AMH), breed, parity, interval from calving to mating start date (MSD), BCS at first insemination at detected estrus (IDE), and pregnancy rate within $84 \mathrm{~d}$ in 2,628 Irish dairy cows ${ }^{1}$

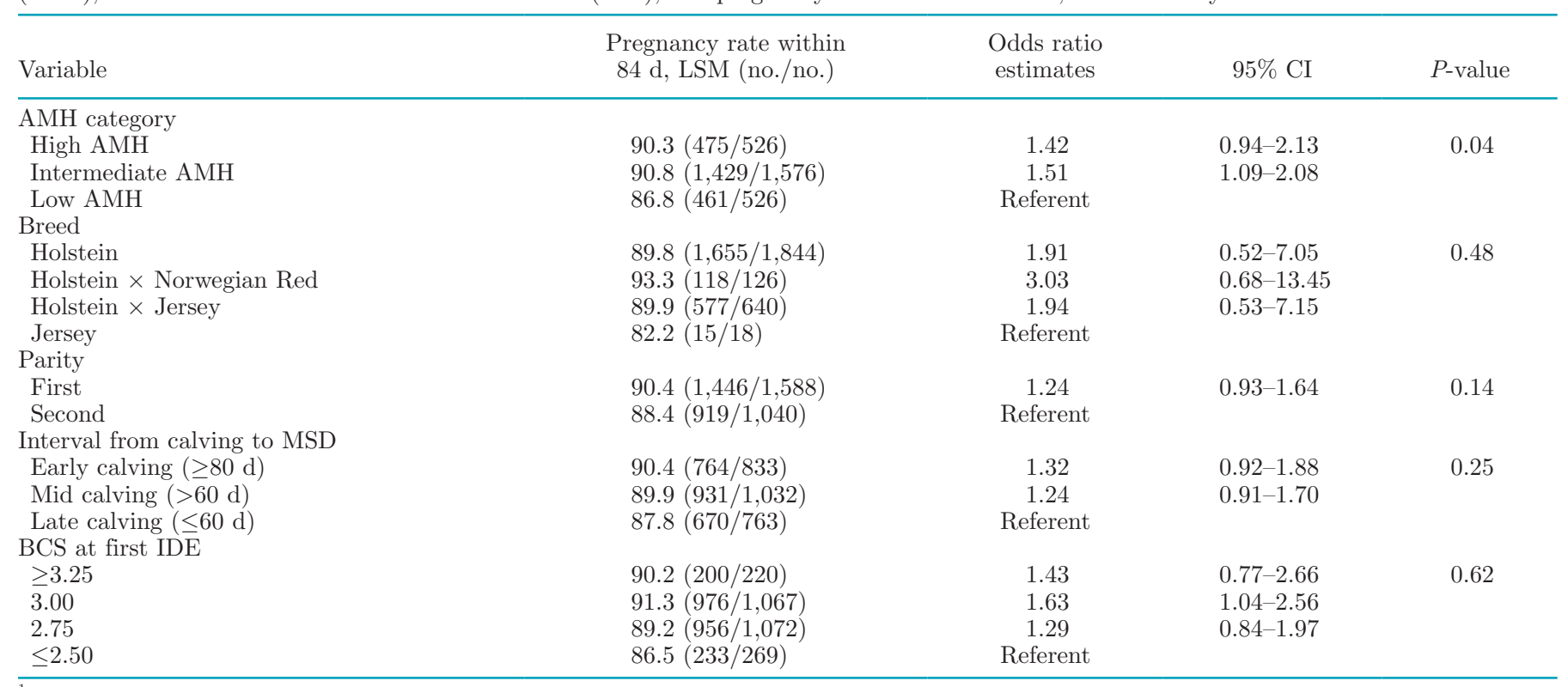

${ }^{1}$ Plasma AMH concentration was determined in 2,628 dairy cows from 35 herds between 7 and $13 \mathrm{~d}$ after first IDE. Cows were ranked across herds in ascending order by plasma $\mathrm{AMH}$ concentration and grouped into low AMH (lowest $20 \%$ values; $\mathrm{n}=526 ;$ mean $=105 ;$ range $=15-150$ $\mathrm{pg} / \mathrm{mL}$ ), intermediate $\mathrm{AMH}$ (intermediate $60 \%$ values; $\mathrm{n}=1,576$; mean $=278$; range $=151-461 \mathrm{pg} / \mathrm{mL}$ ), or high $\mathrm{AMH}$ (highest $20 \%$ values; $\mathrm{n}=526 ;$ mean $=690 ;$ range $=462-2,863 \mathrm{pg} / \mathrm{mL}$ ) categories. Cows with high and intermediate plasma AMH had 1.42- and 1.51-times-greater odds for pregnant within $84 \mathrm{~d}$ of MSD compared with cows with low plasma AMH.

Table 4. Associations among categories of plasma anti-Müllerian hormone (AMH), breed, parity, interval from calving to mating start date (MSD), BCS at first insemination at detected estrus (IDE), and pregnancy to first AI in 2,628 Irish dairy cows ${ }^{1}$

\begin{tabular}{|c|c|c|c|c|}
\hline Variable & $\begin{array}{l}\text { Pregnancy to first AI, } \\
\text { LSM (no./no.) }\end{array}$ & $\begin{array}{l}\text { Odds ratio } \\
\text { estimates }\end{array}$ & $95 \%$ CI & $P$-value \\
\hline \multicolumn{5}{|l|}{ AMH category } \\
\hline Low AMH & $57.5(298 / 526)$ & Referent & & 0.97 \\
\hline \multicolumn{5}{|l|}{ Breed } \\
\hline Holstein & $57.4(1,024 / 1,844)$ & 1.00 & $0.35-2.84$ & \multirow[t]{2}{*}{0.96} \\
\hline Jersey & $57.4(12 / 18)$ & Referent & & \\
\hline \multicolumn{5}{|l|}{ Parity } \\
\hline First & $57.6(923 / 1,588)$ & 1.00 & $0.84-1.19$ & \multirow[t]{2}{*}{0.97} \\
\hline Second & $57.7(594 / 1,040)$ & Referent & & \\
\hline \multicolumn{5}{|l|}{ Interval from calving to MSD } \\
\hline Early calving $(\geq 80 \mathrm{~d})$ & $62.2(533 / 833)$ & 1.57 & $1.26-1.95$ & \multirow[t]{2}{*}{$<0.01$} \\
\hline Mid calving $(>\overline{6} 0 \mathrm{~d})$ & $59.5(605 / 1,032)$ & 1.40 & $1.15-1.70$ & \\
\hline$\leq 2.50$ & $54.8(154 / 269)$ & Referent & & 0.74 \\
\hline
\end{tabular}

${ }^{1}$ Plasma AMH concentration was determined in 2,628 dairy cows from 35 herds between 7 and $13 \mathrm{~d}$ after first IDE. Cows were ranked across herds in ascending order by plasma AMH concentration and grouped into low AMH (lowest $20 \%$ values; $\mathrm{n}=526 ;$ mean $=105 ;$ range $=15-150$ $\mathrm{pg} / \mathrm{mL}$ ), intermediate AMH (intermediate $60 \%$ values; $\mathrm{n}=1,576$; mean $=278$; range $=151-461 \mathrm{pg} / \mathrm{mL}$ ), or high AMH (highest $20 \%$ values; $\mathrm{n}$ $=526 ;$ mean $=690 ;$ range $=462-2,863 \mathrm{pg} / \mathrm{mL}$ ) categories. Cows categorized into early- and mid-calving groups had 1.57- and 1.40-times-greater odds, respectively, for pregnancy to first AI compared with cows categorized as late calving. 
Table 5. Associations among categories of plasma anti-Müllerian hormone (AMH), breed, parity, interval from calving to mating start date (MSD), BCS at first insemination at detected estrus (IDE), and pregnancy rate within $21 \mathrm{~d}$ in 2,628 Irish dairy cows $^{1}$

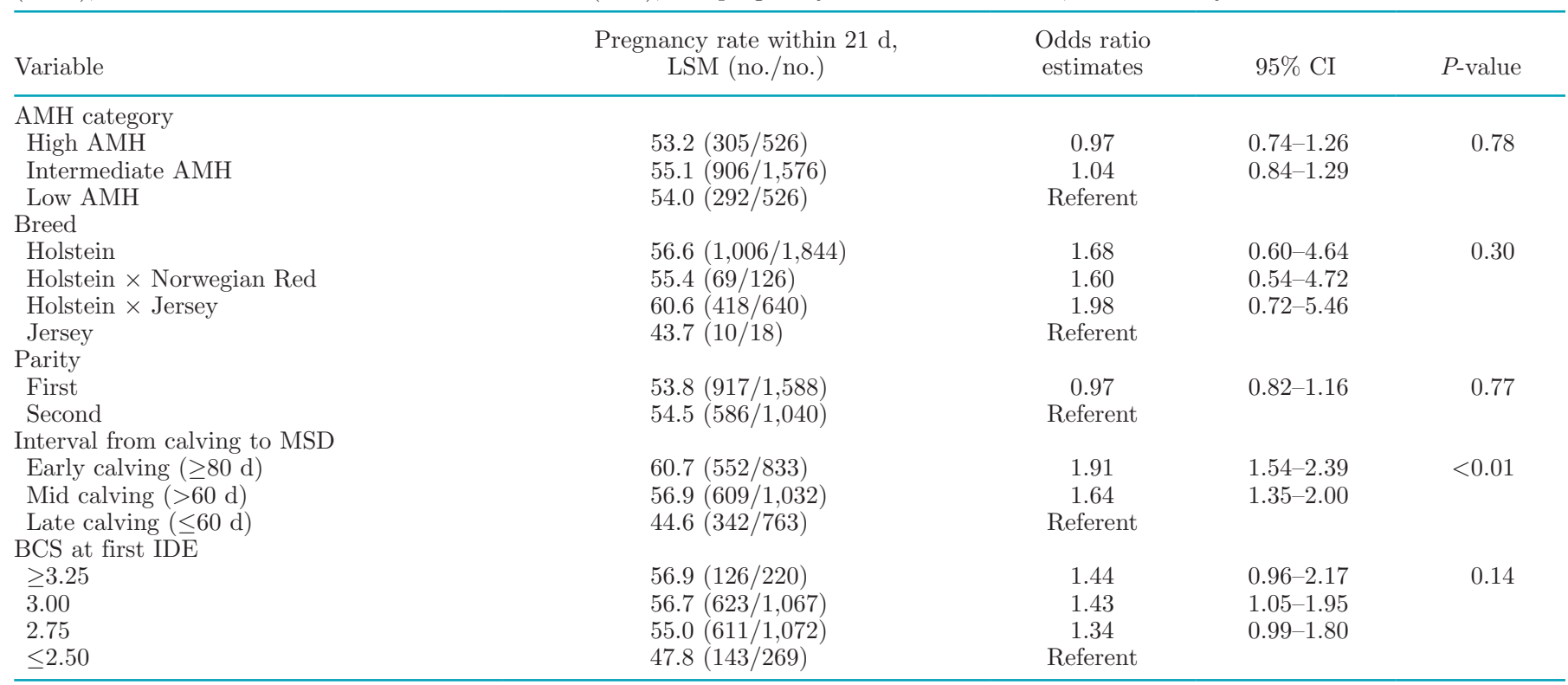

${ }^{1}$ Plasma AMH concentration was determined in 2,628 dairy cows from 35 herds between 7 and 13 d after first IDE. Cows were ranked across herds in ascending order by plasma $\mathrm{AMH}$ concentration and grouped into low $\mathrm{AMH}$ (lowest $20 \%$ values; $\mathrm{n}=526 ;$ mean $=105 ;$ range $=15$ to 150 $\mathrm{pg} / \mathrm{mL}$ ), intermediate $\mathrm{AMH}$ (intermediate $60 \%$ values; $\mathrm{n}=1,576$; mean $=278$; range $=151$ to $461 \mathrm{pg} / \mathrm{mL}$ ), or high AMH (highest $20 \%$ values; $\mathrm{n}=526$; mean $=690 ;$ range $=462$ to $2,863 \mathrm{pg} / \mathrm{mL}$ ) categories. Cows categorized into early- and mid-calving groups had 1.91 - and 1.64 -timesgreater odds, respectively, for pregnant within $21 \mathrm{~d}$ of MSD compared with cows categorized into the late-calving group.

Table 6. Associations among categories of plasma anti-Müllerian hormone (AMH), breed, parity, interval from calving to mating start date (MSD), BCS at first insemination at detected estrus (IDE), and pregnancy rate within $42 \mathrm{~d}$ in 2,628 Irish dairy cows ${ }^{1}$

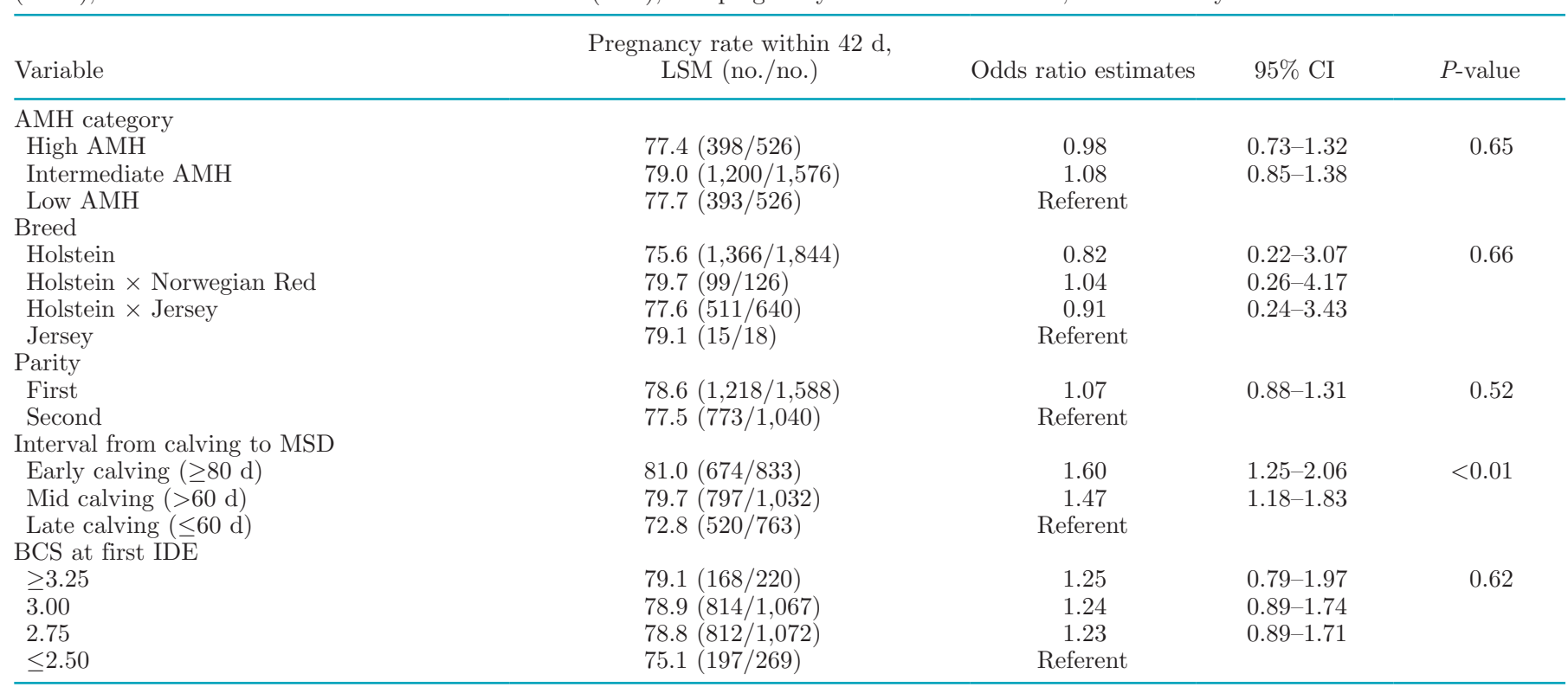

${ }^{1}$ Plasma AMH concentration was determined in 2,628 dairy cows from 35 herds between 7 and $13 \mathrm{~d}$ after first IDE. Cows were ranked across herds in ascending order by plasma AMH concentration and grouped into low AMH (lowest $20 \%$ values; $\mathrm{n}=526 ;$ mean $=105 ;$ range $=15$ to 150 $\mathrm{pg} / \mathrm{mL}$ ), intermediate $\mathrm{AMH}$ (intermediate $60 \%$ values; $\mathrm{n}=1,576$; mean $=278$; range $=151$ to $461 \mathrm{pg} / \mathrm{mL}$ ), or high AMH (highest $20 \%$ values; $\mathrm{n}=526$; mean $=690$; range $=462$ to $2,863 \mathrm{pg} / \mathrm{mL}$ ) categories. Cows categorized into early- and mid-calving groups had 1.60- and 1.47-timesgreater odds, respectively, for pregnant within $42 \mathrm{~d}$ of MSD compared with those categorized into the late-calving group. 
ing low $\mathrm{AFC}$ ( $\leq 15$ follicles of $\geq 3 \mathrm{~mm}$ diameter; $\mathrm{n}=$ $126)$ tended $(P=0.07)$ to be pregnant by the end of the breeding season compared with cows classified as having high AFC ( $\geq 25$ follicles of $\geq 3 \mathrm{~mm}$ diameter; $\mathrm{n}$ $=58$ ) (84 vs. $94 \%$, respectively). Martinez et al. (2016) reported that New Zealand dairy cows (a combination of Holstein and Jersey) with low AFC ( $\leq 20$ follicles of $\geq 2 \mathrm{~mm}$ diameter; $\mathrm{n}=200$ ) had lower P/AI (45 vs. $68 \%$ ), and pregnancy rate within $42 \mathrm{~d}$ (67 vs. $82 \%$ ) and 84 d (80 vs. $91 \%$ ) after the MSD compared with cows with high AFC ( $\geq 30$ follicles of $\geq 2 \mathrm{~mm}$ diameter; $\mathrm{n}=$ 104). It is important to note that the current study and the aforementioned studies (Mossa et al., 2012; Ribeiro et al., 2014; Martinez et al., 2016) were conducted in dairy cows managed under a pasture-based seasonalcalving system. Collectively, results from these studies suggest that cows with low circulating $\mathrm{AMH}$ or AFC and subjected to IDE, natural service, or both have slightly poorer fertility than cows that had intermediate or high AMH or AFC (Mossa et al., 2012; Ribeiro et al., 2014; Martinez et al., 2016). Because the reduction in phenotypic fertility in cows with low plasma $\mathrm{AMH}$ concentration was moderate and only evident at the end of the breeding season in the current study, circulating AMH only partially fulfilled the last criterion (i.e., reproductive phenotype that has strong association with fertility) to become a novel fertility trait for genetic selection in dairy cows.

Hence, we conclude that phenotypic variation in plasma AMH concentration is large, it is moderately heritable, and candidate QTL regions have been identified; however, there are likely only small gains to be made in fertility from selection for greater plasma $\mathrm{AMH}$ concentrations in pasture-based seasonal-calving dairy cows. Nevertheless, because of the positive relationship between circulating $\mathrm{AMH}$ concentrations and ovarian follicular responses to superstimulation (Souza et al., 2015; Hirayama et al., 2017), circulating AMH or its genetic markers (or both) identified in the current and previous studies (Gobikrushanth et al., 2018; Jaton et al., 2018; Nawaz et al., 2018) could be used to identify elite merit donor cows for multiple ovulation and embryo transfer programs in dairy cattle.

\section{ACKNOWLEDGMENTS}

M. Gobikrushanth is a recipient of the TeagascUniversity of Alberta Walsh Fellowship sponsored by Alberta Innovates Biosolutions (Edmonton, Canada). We acknowledge the staff of the Teagasc research dairies and the owners of the commercial dairy farms for their cooperation and participation in the trial. We acknowledge Ansh Labs (Webster, TX) for their in-kind contribution of discounted pricing on AMH assays.
This research was partially funded by the Irish Department of Agriculture, Food and the Marine through RSF project $13 \mathrm{~S} 528$.

\section{REFERENCES}

Baruselli, P. S., E. O. S. Batista, L. M. Vieira, and A. H. Souza. 2015 Relationship between follicle population, AMH concentration and fertility in cattle. Anim. Reprod. 12:487-497.

Batista, E. O. S., G. G. Macedo, R. V. Sala, M. Ortolan, M. F. Sá Filho, T. A. Del Valle, E. F. Jesus, R. Lopes, F. P. Rennó, and P. S. Baruselli. 2014. Plasma antimullerian hormone as a predictor of ovarian antral follicular population in Bos indicus (Nelore) and Bos taurus (Holstein) heifers. Reprod. Domest. Anim. 49:448-452.

Berry, D. P., E. Wall, and J. E. Pryce. 2014. Genetics and genomics of reproductive performance in dairy and beef cattle. Animal 8(Suppl. 1):105-121.

Carthy, T. R., D. P. Ryan, A. M. Fitzgerald, R. D. Evans, and D. P. Berry. 2015. Genetic parameters of ovarian and uterine reproductive traits in dairy cows. J. Dairy Sci. 98:4095-4106.

Cushman, R. A., M. F. Allan, L. A. Kuehn, W. M. Snelling, A. S. Cupp, and H. C. Freetly. 2009. Evaluation of antral follicle count and ovarian morphology in crossbred beef cows: Investigation of influence of stage of the estrous cycle, age, and birth weight. J. Anim. Sci. 87:1971-1980.

Dewailly, D., C. Y. Andersen, A. Balen, F. Broekmans, N. Dilaver, R. Fanchin, G. Griesinger, T. W. Kelsey, A. La Marca, C. Lambalk, H. Mason, S. M. Nelson, J. A. Visser, W. H. Wallace, and R. A. Anderson. 2014. The physiology and clinical utility of antiMullerian hormone in women. Hum. Reprod. Update 20:370-385.

Edmonson, A. J., L. J. Lean, L. D. Weaver, T. Farver, and G. Webster. 1989. A body condition scoring chart for Holstein dairy cows. J. Dairy Sci. 72:68-78.

Gilmour, A. R., B. R. Cullis, S. J. Welham, and R. Thompson. 2009. ASREML. Program user manual. NSW Agriculture, Orange Agricultural Institute, Orange, NSW, Australia.

Gobikrushanth, M., P. A. Dutra, T. C. Bruinje, M. G. Colazo, S. T. Butler, and D. J. Ambrose. 2017. Repeatability of antral follicle counts and anti-Müllerian hormone and their associations determined at an unknown stage of follicular growth and an expected day of follicular wave emergence in dairy cows. Theriogenology 92:90-94.

Gobikrushanth, M., D. C. Purfield, M. G. Colazo, S. T. Butler, Z. Wang, and D. J. Ambrose. 2018. The relationship between serum anti-Müllerian hormone concentrations and fertility, and genome wide associations for anti-Müllerian hormone in Holstein cows. J. Dairy Sci. 101:7563-7574.

Hirayama, H., A. Naito, S. Fukuda, T. Fujii, M. Asada, Y. Inaba, T. Takedomi, M. Kawamata, S. Moriyasu, and S. Kageyama. 2017. Long-term changes in plasma anti-Müllerian hormone concentration and the relationship with superovulatory response in Japanese Black cattle. J. Reprod. Dev. 63:95-100.

Ireland, J. J., G. W. Smith, D. Scheetz, F. Jimenez-Krassel, J. K. Folger, J. L. H. Ireland, F. Mossa, P. Lonergan, and A. C. O. Evans. 2011. Does size matter in females? An overview of the impact of the high variation in the ovarian reserve on ovarian function and fertility, utility of anti-Mullerian hormone as a diagnostic marker for fertility and causes of variation in the ovarian reserve in cattle. Reprod. Fertil. Dev. 23:1-14.

Jaton, C., F. S. Schenkel, M. Sargolzaei, A. Canova, F. Malchiodi, C. A. Price, C. Baes, and F. Miglior. 2018. Genome-wide association study and in silico functional analysis of the number of embryos produced by Holstein donors. J. Dairy Sci. 101:7248-7257.

Jimenez-Krassel, F., J. K. Folger, J. L. H. Ireland, G. W. Smith, X. Hou, J. S. Davis, P. Lonergan, A. C. O. Evans, and J. J. Ireland. 2009. Evidence that high variation in ovarian reserves of healthy young adults has a negative impact on the corpus luteum and endometrium during reproductive cycles of single-ovulating species. Biol. Reprod. 80:1272-1281. 
Jimenez-Krassel, F., D. Scheetz, L. Neuder, J. Ireland, J. Pursley, G. Smith, R. Tempelman, T. Ferris, W. Roudebush, and F. Mossa. 2015. Concentration of anti- Müllerian hormone in dairy heifers is positively associated with productive herd life. J. Dairy Sci. 98:3036-3045.

La Marca, A., and A. Volpe. 2006. Anti-Müllerian hormone (AMH) in female reproduction: is measurement of circulating AMH a useful tool? Clin. Endocrinol. (Oxf.) 64:603-610.

Martinez, M. F., N. Sanderson, L. D. Quirke, S. B. Lawrence, and J. L. Juengel. 2016. Association between antral follicle count and reproductive measures in New Zealand lactating dairy cows maintained in a pasture-based production system. Theriogenology 85:466-475.

Monniaux, D., L. Drouilhet, C. Rico, A. Estienne, P. Jarrier, J. Touzé, J. Sapa, F. Phocas, J. Dupont, R. Dalbiès-Tran, and S. Fabre. 2012. Regulation of anti-Müllerian hormone production in domestic animals. Reprod. Fertil. Dev. 25:1-16.

Mossa, F., F. Carter, S. W. Walsh, D. A. Kenny, G. W. Smith, J. L. Ireland, T. B. Hildebrandt, P. Lonergan, J. J. Ireland, and A. C. O. Evans. 2013. Maternal undernutrition in cows impairs ovarian and cardiovascular systems in their offspring. Biol. Reprod. 88:92.

Mossa, F., S. W. Walsh, S. T. Butler, D. P. Berry, F. Carter, P. Lonergan, G. W. Smith, J. J. Ireland, and A. C. O. Evans. 2012. Low numbers of ovarian follicles $\geq 3 \mathrm{~mm}$ in diameter are associated with low fertility in dairy cows. J. Dairy Sci. 95:2355-2361.

Nawaz, M. Y., F. Jimenez-Krassel, J. P. Steibel, Y. Lu, A. Baktula, N. Vulkasinovic, L. Neuder, J. L. H. Ireland, J. J. Ireland, and R. J. Tempelman. 2018. Genomic heritability and genome-wide association analysis of anti-Müllerian hormone in Holstein dairy heifers. J. Dairy Sci. 101:8063-8075.

Newberry, H. 2016. Use of anti-Müllerian hormone to select for fertility in beef heifers. Animal Science Undergraduate Honors Theses. University of Arkansas, Fayetteville. https://scholarworks.uark .edu/anscuht/9.

Ribeiro, E. S., R. S. Bisinotto, F. S. Lima, L. F. Greco, A. Morrison, A. Kumar, W. W. Thatcher, and J. E. P. Santos. 2014. Plasma anti-Müllerian hormone in adult dairy cows and associations with fertility. J. Dairy Sci. 97:6888-6900

Rico, C., S. Fabre, C. Médigue, N. di Clemente, F. Clément, M. Bontoux, J. L. Touzé, M. Dupont, E. Briant, B. Rémy, J. F. Beckers, and D. Monniaux. 2009. Anti-Müllerian hormone is an endocrine marker of ovarian gonadotropin-responsive follicles and can help to predict superovulatory responses in the cow. Biol. Reprod. 80:50-59.

Rico, C., C. Medigue, S. Fabre, P. Jarrier, M. Bontoux, F. Clement, and D. Monniaux. 2011. Regulation of anti-Mullerian hormone production in the cow: A multiscale study at endocrine, ovarian, follicular, and granulosa cell levels. Biol. Reprod. 84:560-571.

Sargolzaei, M., J. P. Chesnais, and F. S. Schenkel. 2014. A new approach for efficient genotype imputation using information from relatives. BMC Genomics 15:478.

Souza, A. H., P. D. Carvalho, A. E. Rozner, L. M. Vieira, K. S. Hackbart, R. W. Bender, A. R. Dresch, J. P. Verstegen, R. D. Shaver, and M. C. Wiltbank. 2015. Relationship between circulating antiMüllerian hormone (AMH) and superovulatory response of highproducing dairy cows. J. Dairy Sci. 98:169-178.

Taniguchi, H., J. Komiyama, R. S. Viger, and K. Okuda. 2009. The expression of the nuclear receptors NR5A1 and NR5A2 and transcription factor GATA6 correlated with steroidogenic gene expression in the bovine corpus luteum. Mol. Reprod. Dev. 76:873-880.

Walsh, S. W., F. Mossa, S. T. Butler, D. P. Berry, D. Scheetz, F. Jimenez-Krassel, R. J. Tempelman, F. Carter, P. Lonergan, A. C Evans, and J. J. Ireland. 2014. Heritability and impact of environmental effects during pregnancy on antral follicle count in cattle. J. Dairy Sci. 97:4503-4511.

Yang, J., B. Benyamin, B. P. McEvoy, S. Gordon, A. K. Henders, D. R. Nyholt, P. A. Madden, A. C. Heath, N. G. Martin, G. W. Montgomery, M. E. Goddard, and P. M. Visscher. 2010. Common SNPs explain a large proportion of the heritability for human height. Nat. Genet. 42:565-569.

Yang, J., S. H. Lee, M. E. Goddard, and P. M. Visscher. 2011. GCTA: A tool for genome-wide complex trait analysis. Am. J. Hum. Genet. 88:76-82.

Zhang, B., F. Penagaricano, A. Driver, H. Chen, and H. Khatib. 2011. Differential expression of heat shock protein genes and their splice variants in bovine preimplantation embryo. J. Dairy Sci. 94:41744182 .

\section{ORCIDS}

M. Gobikrushanth ำ https://orcid.org/0000-0002-5059-4631

M. M. Herlihy @ https://orcid.org/0000-0002-3886-0300

J. Kenneally @ https://orcid.org/0000-0001-9033-1927

M. G. Colazo @ (ㄴ https://orcid.org/0000-0002-7793-6515

D. J. Ambrose @ https://orcid.org/0000-0002-3313-7199

S. T. Butler ๑ https://orcid.org/0000-0003-1542-8344 